\title{
Frequency of temporomandibular disorders in asymptomatic removable partial and complete denture wearers
}

doi:10.1533/abbi.2006.054

\author{
N. Dulčić, V. Jerolimov and J. Pandurić \\ Department of Prosthetic Dentistry, Faculty of Dentistry, University of Zagreb, Croatia
}

\begin{abstract}
A dogmatic view on occlusion as the main aetiological factor for temporomandibular disorder (TMD) has been present in the literature for a long time, but a direct scientific correlation between occlusal disorders and TMD has never been proven. The purpose of this study was to determine the frequency of TMD signs and tissue-specific diagnoses in a population of 164 asymptomatic participants, 70 removable partial denture wearers and 94 complete denture wearers of an average age of 61.3 years, by means of clinical manual functional analysis. TMD was found in $42.1 \%$ of the participants. No statistically significant difference in the occurrence of TMD was found between removable partial and complete denture wearers and between genders $(P>0.05)$. The most frequent tissue-specific diagnoses were osteoarthrosis (11\%), total anterior disc displacement $(9.1 \%)$ and partial anterolateral disc displacement $(8.5 \%)$. The frequency of tissue-specific diagnoses was also not influenced by the type of prosthetic replacements.
\end{abstract}

Key words: Manual functional analysis, occlusion, tissue-specific diagnoses, temporomandibular disorder.

\section{INTRODUCTION}

There are many studies in the literature showing a frequent incidence of temporomandibular disorders (TMDs) in general populations and trying to establish their causes and characteristics (Agerberg and Inkapool 1990; Jagger and Wood 1992; Wanman 1995; List and Dworkin 1996; Matsuka et al. 1996; Schmitter et al. 2005). In the last few decades, many authors investigated the aetiology, diagnostics and treatment of TMD. TMD has endogenous and exogenous causes that affect the neurogenous, myogenous and arthrogenous parts of the masticatory system (Zarb et al. 1994). The endogenous aetiological factors comprise idiopathic, systemic, psychosomatic and psychosocial causes of TMD, and the exogenous aetiological factors include trauma and occlusal disorders (Bumann and Lotzmann 2002).

The disorder of the arthrogenous intracapsular part of the masticatory system is called internal derangement $(I D)$

Corresponding Author:

N. Dulčić

Department of Prosthodontics

School of Dentistry, University of Zagreb

Gundulićeva 5, HR-10000, Zagreb, Croatia

Tel: +385-1-480-21-25, Fax: +385-1-480-21-59

Email: niksa.dulcic@zg.htnet.hr
(Farrar 1971). Katzberg et al. (1979) described ID of the temporomandibular joint (TMJ) as a disturbed relation between the disk and the mandibular condyle, fossa and articular eminence, whereas Westesson et al. (1989) described it as a localized mechanical fault that disturbs the normal function of the TMJ.

A dogmatic view on occlusion as the main aetiological factor of TMD has been present in the literature for a long time, but a direct scientific correlation between occlusal disorders and TMD has never been proven (Roberts et al. 1987; Seligman et al. 1988; Cacchiotti et al. 1991; Seligman and Pullinger 1991; Pullinger et al. 1993; McNamara et al. 1995; Raustia et al. 1995; Henrikson et al. 1997; Celic and Jerolimov 2002). On the basis of the application of a multifactorial logistic regression analysis, research has shown that only $5 \%$ to $27 \%$ of a TMD sample can be associated with occlusal factors (De Laat et al. 1986; Pullinger et al. 1993; Pullinger and Seligman 2000).

Some studies examined the incidence of TMD in relation to subjects' gender, providing rather contradictory results (Pullinger et al. 1988; Huber and Hall 1990; Lundh and Westesson 1991; Kuttila et al. 1998; Rutkiewicz et al. 2006). Both Carlsson (1976) and Choy and Smith (1980) found an increased risk of occurrence of TMD signs in completely edentulous subjects in relation to dentate subjects. They occurred in $25 \%$ to $32 \%$ of complete denture wearers (Hansen and Axin 1984; Sakurai et al. 1988). 
Sidelsky and Clayton (1990) found clinical signs of TMD in $46 \%$ of prosthetically treated subjects of an average age of 58 years. According to the studies by Matsuka et al. (1996), Papas et al. (1991, p. 7-9) and Iacopino and Wathen (1993), osteoarthrosis is the most frequent intracapsular change in the TMJ, which affects population older than 60. Holmlund et al. (1989) found osteoarthrosis in $77 \%$ of the subjects aged 43 on average, whereas Öberg et al. (1971) found it in $41 \%$ of cadavers on autopsy. Anterior disc displacement was determined in $15 \%$ to $55 \%$ of the TMJs examined by clinical investigation and magnetic resonance imaging (MRI) (Kircos et al. 1987; Westesson et al. 1989; De Mot et al. 1994; Tallents et al. 1996; Whyte et al. 2006). However, the findings of such studies have considerable variations due to differences in the terminology of description, data collection, technical and analytic approaches and individual factors selected for the study (McNeill 1993).

Although MRI has become a standard procedure in the diagnostics of ID of the TMJ (Westesson et al. 1987; Katzberg et al. 1996; Eberhard et al. 2000), clinical functional analyses have not lost their importance, primarily because due to financial and technical reasons, it is often impossible to apply MRI in everyday practice. Furthermore, the research by Widmalm et al. (2006) stated that diagnosis of TMD on the basis of MRI protocols made by a single examiner should not be accepted as criterion standard with regard to TMJ disorders. These arguments encouraged the choice of clinical manual functional analysis according to Bumann and Groot Landeweer (1992a, $1992 b)$ as the examination procedure in this study.

Clinical manual functional analysis comprises orthopaedic test procedures that examine the incidence, intensity and time of development of clinical signs of TMD using specific techniques of loading the structures within the joint capsule (Bumann and Lotzmann 2002). Lobbezoo-Scholte et al. (1993, 1995) have already shown the diagnostic value of orthopaedic tests in the TMD diagnostics. Bumann and Zaboulas (1996) proved the validity and reliability of manual functional analysis by comparison of the MRI results and the manual functional analysis results of their study. A correspondence of the results was found in $80 \%$ to $94 \%$ of the subjects.

Manual functional analysis was used for the purpose of this study to determine the frequency of signs of TMD and tissue-specific diagnoses in a population of asymptomatic participants, removable partial and complete denture wearers. A further aim was to determine a correlation between the incidence of tissue-specific diagnoses in relation to the participants' gender and the side of TMD occurrence.

\section{MATERIALS AND METHODS}

The study was conducted by a single examiner on patients at the Clinic of the Department of Prosthetic Dentistry, Faculty of Dentistry, University of Zagreb, Croatia, in the course of 4 months. Two hundred patients, remov- able partial or complete denture wearers, were randomly chosen during their recall visits. An examination list made according to the Principles of Helsinki/Belmont was used for the purpose of the study (Dulčic 2001). Personal data of each participant were taken first, followed by anamnestic data. The criteria of inclusion of the patients in the study were the following: a patient's voluntary consent to participate in the study, and that a patient had been a complete or removable partial denture wearer for at least 1 year. Thirty-six patients who reported at least one of the following factors were excluded from the study: TMD symptoms (pain, clicking and crepitation in the TMJ area), trauma of the orofacial system, previous orthodontic treatment, impossibility of opening the mouth for more than $40 \mathrm{~mm}$ or mandibular deviation at an opening movement. Clinical examination of the signs of TMD was carried out on the patients that met the criteria for participation in this study by means of manual functional analysis. The sample composed of 164 asymptomatic participants aged between 42 and 88 (mean age $=61.3)-70$ removable partial denture (RPD) wearers and 94 complete denture (CD) wearers; there were 52 men and 112 women.

Manual functional analysis according to Bumann and Lotzmann (2002) was used for individual examination of the structures within the TMJ and masticatory muscles. It consists of two parts: unspecific examination and specific examination. Unspecific examination comprises examination of active and passive mandibular movements and isometric strain of the masticatory muscles (Bumann and Groot Landeweer 1992a, 1992b; Bumann and Lotzmann 2002). It enables basic distinction of the causes of the disorders experienced by patients, that is, it determines whether the cause is of arthrogenous, myogenous or neurogenous origin. Specific examination comprises several techniques that include passive compressions, tractions, translations, dynamic compressions and translations, and joint and muscle palpation (Bumann and Groot Landeweer 1992a, 1992b; Bumann and Lotzmann 2002). Passive compressions, tractions and translations are commonly called TMJ examination techniques. They examine TMJ movements, the so-called joint play. These techniques are used for distinction of the changes in the area of joint surfaces, joint ligaments, joint capsule and the bilaminar zone (Bumann et al. 1993; Bumann and Lotzmann 2002). Diagnosis of functional disorders of individual masticatory muscles is made by palpation, whereas functional disorders of the joint are diagnosed by means of dynamic compressions and translations. The moment, intensity and quality of clicking in the pathway of the condyles are observed after each compression and translation, and compared with the results of active movements without manipulation. The occurrence of pain and crepitation is also recorded.

Clicking, crepitation and pain are clinical signs of specific significance for clinical diagnosis of TMD. Clicking is considered to be a sign of disk displacement, crepitation is considered as a sign of osteoarthrosis, and pain in the area 
of masticatory muscles or the TMJ as a sign of an acute inflammatory process. The tissue-specific diagnoses that were made using manual functional analysis in this study are shown in Table 1.

The data collected in this study were stored in the computer for each participant and analysed using the SPSS 12.0 for Windows program. The results were presented by descriptive statistics. The chi-square test for independent samples and Fischer's test were used for establishing the significance of the difference in the frequency of tissue-specific diagnoses, depending on different groups of the participants (in relation to the type of prosthetic replacement: RPD and CD; the side of TMD occurrence: unilateral/bilateral; and the participants' gender). The significance levels of $P>0.05, P<0.05$ and $P<0.01$ were established.

\section{RESULTS}

In this study, TMD was found in $69(42.1 \%)$ participants and in $108(32.9 \%)$ TMJs. TMD was diagnosed in 50 TMJs of $31(44.3 \%)$ RPD wearers and in 58 TMJs of $38(40.4 \%)$ CD wearers. No statistically significant difference in the total occurrence of TMD was found between RPD and CD wearers $(P>0.05)$. Distribution according to gender showed that TMD was found in $49(43.7 \%)$ women and $20(38.5 \%)$ men. No statistically significant difference in the total occurrence of TMD was found between genders $(P>0.05)$. In 30 participants, TMD was found unilaterally, and in 39 participants bilaterally. No statistically significant difference in the total occurrence of TMD was found in relation to the side of TMD occurrence $(P>0.05)$. The tissue-specific diagnoses of TMJ disorders were established on the basis of the findings achieved by manual functional analysis. Out of 69 participants with a tissue-specific diagnosis, 9 participants had diagnoses of myogenous origin and others had diagnoses of arthrogenous origin. A statistically significant difference in the occurrence of tissue-specific diagnoses was found between myogenous and arthrogenous diagnoses $(P<0.01)$. The most frequent tissue-specific diagnoses in the total sample were osteoarthrosis in $18(11 \%)$ participants, total anterior disc displacement in $15(9.1 \%)$ participants and partial anterolateral disc displacement in $14(8.5 \%)$ participants, whereas other tissue-specific diagnoses occurred in $22(13.4 \%)$ participants (Table 1$)$. There were no signs of the following tissue-specific diagnoses: osteoarthritis, partial anteromedial disc displacement, disc displacement with adhesion, cartilage hypertrophy, disc displacement with terminal reposition and capsulitis. In relation to the type of prosthetic replacement, a statistically significant difference was found between RPD and CD wearers in the occurrence of osteoarthrosis $(P<0.05)$, myofascitis of the lateral pterygoidal muscle $(P<0.05)$ and partial anterolateral disc displacement $(P<0.01)$. According to the participants' gender, a statistically significant difference was found between men and women in the occur- rence of myofascitis of the lateral pterygoidal muscle $(P$ $<0.05)$ and capsulitis of the lateral ligament $(P<0.05)$. No statistically significant difference in the frequency of tissue-specific diagnoses was found in relation to the side of TMD occurrence $(P>0.05)$.

\section{DISCUSSION}

Studies on various populations have shown that clinical signs of TMD occur in 14\% to $80 \%$ of subjects (Agerberg and Inkapool 1990; Jagger and Wood 1992; Wanman 1995; Matsuka et al. 1996; List and Dworkin 1996; Schmitter et al.2005). In this study, clinical signs of TMD were found in $42.1 \%$ of the participants, which is midway between the large range of the results obtained by other authors. This large range of the results can be explained by the application of different methods of clinical functional analysis of the masticatory system.

In this study, $44.3 \%$ of the RPD wearers and $40.4 \%$ of the CD wearers had clinical signs of TMD, which corresponds to the study conducted by Hansson and Öberg (1977) and Sidelsky and Clayton (1990), and which indicates a slightly higher percentage than that found by Hansen and Axin (1984) and Sakurai et al. (1988). A higher frequency of clinical signs of TMD was found in RPD wearers than in $\mathrm{CD}$ wearers, which can be explained by preserved teeth in the supporting zones, but no statistically significant difference was found between RPD and $\mathrm{CD}$ wearers in the occurrence of TMD $(P>0.05)$. Consequently, if a prosthetic replacement is fabricated correctly, there is no difference in the occurrence of TMD between RPD and CD wearers, and long-span replacements have no aetiological importance for the development of TMJ disorders.

Although many studies indicated a higher frequency of TMD signs in females (Pullinger et al. 1988; Huber and Hall 1990; Wanman 1995; Kuttila et al. 1998; Rutkiewicz et al. 2006) than in males, this study did not report any statistically significant difference in the occurrence of clinical signs of TMD and tissue-specific diagnoses between genders $(P>0.05)$. This is in accordance with the results by Lundh and Westesson (1991), Carlsson (1999) and Rutkiewicz et al. (2006). The reason for this could be the same course of aging processes in both genders of elderly populations.

No statistically significant difference in the occurrence of TMD was found in relation to the side of occurrence $(P>0.05)$, and tissue-specific diagnoses were found bilaterally in $56 \%$ of the participants.

The occurrence of the tissue-specific diagnoses of TMJ disorders from this study was compared to the results achieved mainly by means of MRI by other authors. A statistically significant difference was found in the occurrence of myogenous and arthrogenous diagnoses $(P<0.01)$. This result can be explained by a higher pain tolerance and a higher biological capacity of adaptation in asymptomatic participants with respect to a higher frequency of 
Table 1 Frequency of tissue-specific diagnoses in relation to the type of prosthetic replacement, side of TMD occurrence and participants' gender ${ }^{\mathrm{a}}$.

\begin{tabular}{|c|c|c|c|c|c|c|c|c|c|c|}
\hline \multirow[b]{2}{*}{$\begin{array}{l}\text { Tissue-specific } \\
\text { diagnosis }\end{array}$} & \multicolumn{2}{|c|}{$\operatorname{RPD}(n=70)$} & \multicolumn{2}{|c|}{$\mathrm{CD}(n=94)$} & \multicolumn{2}{|c|}{ Total $(N=164)$} & \multicolumn{2}{|c|}{ Total $(N=164)$} & \multicolumn{2}{|c|}{ Total $(N=164)$} \\
\hline & $\begin{array}{l}\text { Participants } \\
(n=70)\end{array}$ & $\begin{array}{l}\text { Joints } \\
(n=140)\end{array}$ & $\begin{array}{l}\text { Participants } \\
(n=164)\end{array}$ & $\begin{array}{l}\text { Joints } \\
(n=328)\end{array}$ & $\begin{array}{l}\text { Participants } \\
(n=94)\end{array}$ & $\begin{array}{l}\text { Joints } \\
(n=188)\end{array}$ & Unilateral & Bilateral & $\begin{array}{l}\text { Female } \\
(n=112)\end{array}$ & $\begin{array}{l}\text { Male } \\
(n=52)\end{array}$ \\
\hline \multicolumn{11}{|l|}{ Myogenous } \\
\hline $\begin{array}{l}\text { Myofascitis of } \\
\text { contractor muscles }\end{array}$ & 0 & 0 & 2 & 4 & 2 & 4 & 0 & 2 & 2 & 0 \\
\hline $\begin{array}{l}\text { Myofascitis of the } \\
\text { lateral pterygoidal } \\
\text { muscle }\end{array}$ & 5 & 7 & 2 & 4 & 7 & 11 & 3 & 4 & 7 & 0 \\
\hline $\begin{array}{l}\text { Capsulitis of the } \\
\text { lateral ligament }\end{array}$ & 3 & 3 & 2 & 2 & 5 & 5 & 5 & 0 & 5 & 0 \\
\hline Osteoarthrosis & 4 & 8 & 14 & 21 & 18 & 29 & 7 & 11 & 10 & 8 \\
\hline \multicolumn{11}{|l|}{ Arthrogenous } \\
\hline Disc hypermobility & 0 & 0 & 2 & 4 & 2 & 4 & 0 & 2 & 2 & 0 \\
\hline $\begin{array}{r}\text { Partial anterolateral } \\
\text { disc displacement }\end{array}$ & 11 & 19 & 3 & 3 & 14 & 22 & 6 & 8 & 11 & 3 \\
\hline $\begin{array}{l}\text { Total anterior disc } \\
\text { displacement }\end{array}$ & 6 & 9 & 9 & 14 & 15 & 23 & 7 & 8 & 8 & 7 \\
\hline $\begin{array}{l}\text { Condyle } \\
\text { hypermobility }\end{array}$ & 2 & 4 & 4 & 6 & 6 & 10 & 2 & 4 & 4 & 2 \\
\hline Total & 31 & 50 & 38 & 58 & 69 & 108 & 30 & 39 & 49 & 20 \\
\hline
\end{tabular}

${ }^{\mathrm{a}} \mathrm{RPD}=$ removable partial denture; $\mathrm{CD}=$ complete denture. 
myogenous diagnoses in symptomatic groups of subjects (Cacchiotti et al. 1991; Tallents et al. 1996). No statistically significant difference was established in the occurrence of myogenous and arthrogenous diagnoses between RPD and CD wearers, which is in accordance with the findings by Roberts et al. (1987) and Lundh and Westesson (1991). In this study, osteoarthrosis was diagnosed in $11 \%$ of the participants, which corresponds to the results obtained by Kopp (1977), Papas et al. (1991, p. 7-9), Iacopino and Wathen (1993) and Matsuka et al. (1996), while other authors found osteoarthrosis in $77 \%$ of the joint surfaces (Öberg et al. 1971; Holmlund et al. 1989). This study reported anterolateral displacement as the most frequent disc displacements, which shows that stratum inferius of the bilaminar zone is a tissue often damaged by TMD. Other clinical and MRI studies indicated similar results (Kircos et al. 1987; Westesson et al. 1989; De Mot et al. 1994; Tallents et al. 1996; Whyte et al. 2006).

\section{ACKNOWLEDGMENTS}

This study was carried out within the scientific project no. 065010 of the Ministry of Science and Technology of the Republic of Croatia, entitled 'Occlusion and craniomandibular dysfunctions', and headed by Prof Josip Pandurić, $\mathrm{PhD}$.

\section{REFERENCES}

Agerberg G, Inkapool I. 1990. Craniomandibular disorders in an urban Swedish population. 7 Craniomandib Disord, 4:154-64.

Bumann A, Groot Landeweer G. 1992a. Manuelle Funktionsanalyse: Basisuntersuchung. Phillip F, 4:137-42.

Bumann A, Groot Landeweer G. 1992b. Die 'Manuelle Funktionsanalyse': 'Erweiterte Untersuchung'. Phillip F, 5:207-14.

Bumann A, Groot Landeweer G, Lotzmann U. 1993. Die Bedeutung der Gelenkspieltechniken im Rahmen der manuellen Funktionsanalyse. ZWR, 5:338-42.

Bumann A, Lotzmann U. 2002. TMJ Disorders and Orofacial Pain - The Role of Dentistry in a Multidisciplinary Diagnostic Approach. New York: Thieme.

Bumann A, Zaboulas D. 1996. Reliability of manual examination techniques for diagnosis of disc displacement. Eur 7 Orthod, 18:511.

Cacchiotti DA, Plesh O, Bianchi P, et al. 1991. Signs and symptoms in samples with and without temporomandibular disorders. 7 Craniomandib Disord, 5:167-72.

Carlsson GE. 1976. Symptoms of mandibular dysfunction in complete denture wearers. $\mathcal{F}$ Dent, 4:265-70.

Carlsson GE. 1999. Epidemiology and treatment need for temporomandibular disorders. 7 Orofac Pain, 13:232-7.

Celic R, Jerolimov V. 2002. Association of horizontal and vertical overlap with prevalence of temporomandibular disorders. $\mathcal{F}$ Oral Rehabil, 29: 588-93.

Choy E, Smith OE. 1980. The prevalence of temporomandibular joint disturbances in complete denture patients. $7 \mathrm{Oral}$ Rehabil, 7:331-52.
De Laat A, Van Steenberghe D, Lasaffre E. 1986. Occlusal relationships and TMJ dysfunction; part II: Correlations between occlusal and articular parameters and symptoms of TMJ dysfunction by means of stepwise logistic regression. $\mathcal{F}$ Prosthet Dent, 55:116-21.

De Mot B, Casselman J, De Boever J. 1994. Pseudodynamic magnetic resonance imaging in the diagnosis of temporomandibular joint dysfunction. 7 Prosthet Dent, 72:309-13

Dulčić N. 2001. Correlation Between Changes in Temporomandibular Joint Disc and Tooth Loss [master's thesis]. Zagreb: Faculty of Dentistry.

Eberhard D, Bantleon HP, Steger W. 2000. Functional magnetic resonance imaging of temporomandibular joint disorders. Eur F Orthod, 22:489-97.

Farrar WB. 1971. Diagnosis and treatment of anterior dislocation of the articular disc. $N Y \mathcal{F}$ Dent, 41:348-51.

Hansen CA, Axin S. 1984. Incidence of mandibular dysfunction symptoms in individuals who remove their complete dentures during sleep. 7 Prosthet Dent, 51:16-18.

Hansson T, Öberg T. 1977. Arthrosis and deviation in form in the temporomandibular joint: A macroscopic study on a human autopsy material. Acta Odontol Scand, 5:167-74.

Henrikson T, Ekberg EC, Nilner M. 1997. Symptoms and signs of temporomandibular disorder in girls with normal occlusion and class II occlusion. Acta Odontol Scand, 55:229-35.

Holmlund A, Hellsing G, Axelsson S. 1989. The temporomandibular joint: A comparison of clinical and arthroscopic findings. 7 Prosthet Dent, 62:61-65.

Huber MA, Hall EH. 1990. A comparison of the signs of temporomandibular joint dysfunction and occlusal discrepancies in a symptom-free population of men and women. Oral Surg Oral Med Oral Pathol, 70:180-3.

Iacopino AM, Wathen WF. 1993. Craniomandibular disorders in geriatric patient. 7 Orofac Pain, 7:38-53.

Jagger RG, Wood C. 1992. Signs and symptoms of temporomandibular joint dysfunction in Saudi Arabian population. 7 Oral Rehabil, 19:353-9.

Katzberg RW, Dolwick MF, Bales DJ, et al. 1979. Arthrotomography of the temporomandibular joint: New technique and preliminary observations. Am $\mathcal{F}$ Roentgenol, 132:949-55.

Katzberg RW, Westesson P, Tallents RH, et al. 1996. Anatomic disorders of the temporomandibular joint disc in asymptomatic subjects. 7 Oral Maxillofac Surg, 54:147-53

Kircos LT, Ortendahl DA, Mark AS, et al. 1987. Magnetic resonance imaging of the TMJ disk in asymptomatic volunteers. 7 Oral Maxillofac Surg, 45:852-4.

Kopp S. 1977. Clinical findings in temporomandibular joint osteoarthrosis. Scand 7 Dent Restor, 85:434-43.

Kuttila M, Niemi PM, Kuttila S, et al. 1998. TMD treatment need in relation to age, gender, stress, and diagnostic subgroup. $\mathcal{F}$ Orofac Pain, 12:67-74.

List T, Dworkin SF. 1996. Comparing TMD diagnoses and clinical findings at Swedish and US TMD centers using research diagnostic criteria for temporomandibular disorders. 7 Orofac Pain, 10:240-53.

Lobbezoo-Scholte AM, Lobbezoo F, Steenks MH, et al. 1995. Diagnostic subgroups of craniomandibular disorders; part II: Symptom profiles. 7 Orofac Pain, 9:37-43. 
Lobbezoo-Scholte AM, Steenks MH, Faber JA, et al. 1993. Diagnostic value of orthopedic tests in patients with temporomandibular disorders. $\mathcal{F}$ Dent Restor, 72:1443-53.

Lundh H, Westesson PL. 1991. Clinical signs of temporomandibular joint internal derangement in adults. Oral Surg Oral Med Oral Pathol, 72:637-41.

Matsuka Y, Yatani H, Kuboki T, et al. 1996. Temporomandibular disorders in the adult population of Okayama City, Japan. Cranio, 14:158-62.

McNamara JA, Seligman DA, Okeson JP. 1995. Occlusion, orthodontic treatment, and temporomandibular disorders: A review. F Orofac Pain, 9:73-90.

McNeill C. 1993. Temporomandibular Disorders: Guidelines for Classification, Assessment, and Management. Chicago: Quintessence Publishing Co.

Öberg T, Carlsson G, Fajers C. 1971. The temporomandibular joint: A morphologic study on a human autopsy material. Acta Odontol Scand, 29:349-84.

Papas AS, Niessen LC, Chauncey HH. 1991. Geriatric Dentistry: Aging and Oral Health. St Louis: Mosby.

Pullinger AG, Seligman DA. 2000. Quantification and validation of predictive values of occlusal variables in TMD using a multifactorial analysis. 7 Prosthet Dent, 61:66-75.

Pullinger AG, Seligman DA, Gornbein JA. 1993. A multiple logistic regression analysis of the risk and relative odds ratio of temporomandibular disorders as a function of common occlusal features. 7 Dent Restor, 72:968-79.

Pullinger AG, Seligman DA, Solberg WK. 1988. Temporomandibular disorders; part I: Functional status, dentomorphologic features, and sex differences in a nonpatient population. 7 Prosthet Dent, 59:228-35.

Raustia AM, Pirttiniemi PM, et al. 1995. Correlation of occlusal factor and condyle position asymmetry with signs and symptoms of temporomandibular disorders in young adults. Cranio, 13:152-6.

Roberts CA, Tallents RH, Katzberg RW, et al. 1987. Comparison of internal derangement of the TMJ with occlusal findings. Oral Surg Oral Med Oral Pathol, 63:645-50.

Rutkiewicz T, Kononen M, Suominen-Taipale L, et al. 2006. Occurrence of clinical signs of temporomandibular disorders in adult Finns. $\mathcal{F}$ Orofac Pain, 20:208-17.
Sakurai K, San Giacomo T, Arbree NS, et al. 1988. A survey of temporomandibular joint dysfunction in completely edentulous patients. $\mathcal{F}$ Prosthet Dent, 59:81-85.

Schmitter M, Rammelsberg P, Hassel A. 2005. The prevalence of signs and symptoms of temporomandibular disorders in very old subjects. F Oral Rehabil, 32:467-73.

Seligman DA, Pullinger AG. 1991. The role of functional occlusal relationships in temporomandibular disorders: A review. $\mathcal{F}$ Craniomandib Disord, 5:265-79.

Seligman DA, Pullinger AG, Solberg WK. 1988. Temporomandibular disorders; part III: Occlusal and articular factors associated with muscle tenderness. $\mathcal{F}$ Prosthet Dent, 59:483-9.

Sidelsky H, Clayton JA. 1990. A clinical study of joint sounds in subjects with restored occlusions. 7 Prosthet Dent, 63:580-6.

Tallents RH, Katzberg RW, Murphy W, et al. 1996. Magnetic resonance imaging findings in asymptomatic volunteers and symptomatic patients with temporomandibular disorders. $\mathcal{F}$ Prosthet Dent, 75:529-33.

Wanman A. 1995. The relationship between muscle tenderness and craniomandibular disorders: A study of 35-year-olds from the general population. 7 Orofac Pain, 9:235-43.

Westesson PL, Eriksson L, Kurta K. 1989. Reliability of a negative clinical examination: Prevalence of disk displacement in asymptomatic temporomandibular joints. Oral Surg Oral Med Oral Pathol, 68:551-4.

Westesson PL, Katzberg RW, Tallents RH, et al. 1987. Temporomandibular joint: Comparison of MR images with cryosectional anatomy. Radiology, 164:59-64.

Whyte AM, McNamara D, Rosenberg I, et al. 2006. Magnetic resonance imaging in the evaluation of temporomandibular joint disc displacement - A review of 144 cases. Int 7 Oral Maxillofac Surg, 35:696-703.

Widmalm SE, Brooks SL, Sano T, et al. 2006. limitation of the diagnostic value of MR images for diagnosing temporomandibular joint disorders. Dentomaxillofac Radiol, $35: 334-8$.

Zarb GA, Carlsson GE, Sessle B, et al. 1994. Temporomandibular Joint and Masticatory Muscle Disorders. St Louis: CV Mosby. 

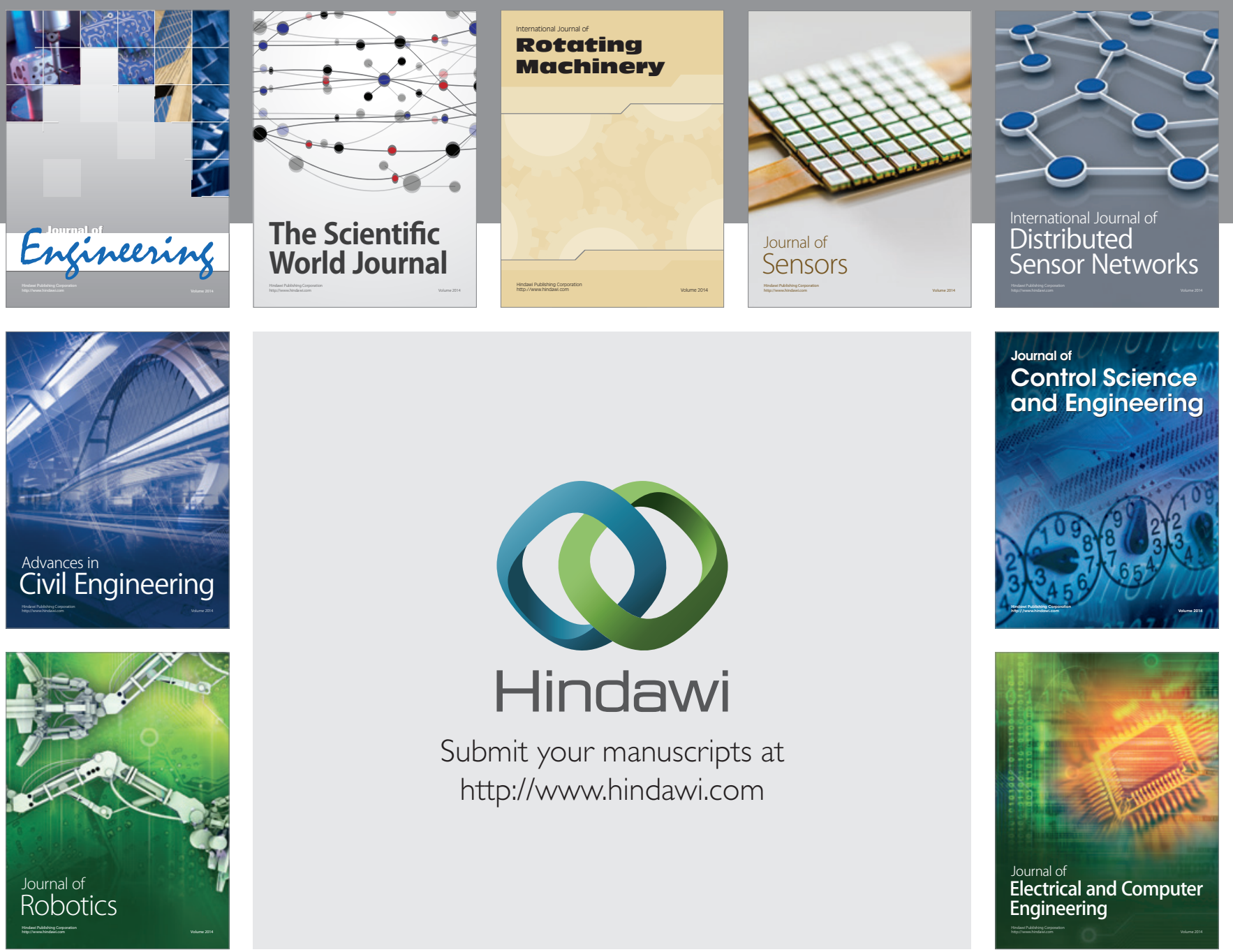

Submit your manuscripts at

http://www.hindawi.com
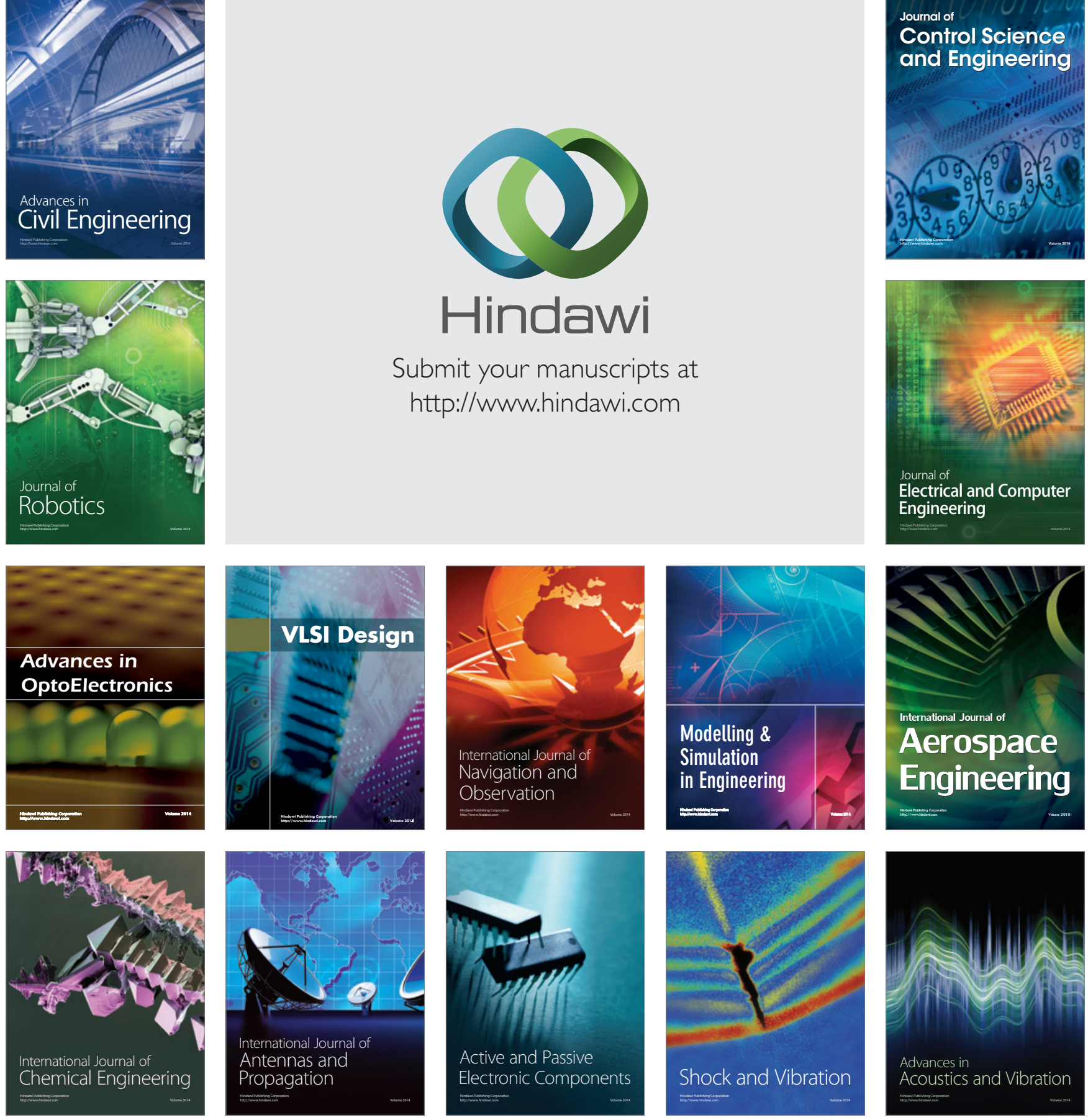